\title{
Weblog Campaigning in the German Bundestag Election 2005
}

\author{
Steffen Albrecht \\ Maren Lübcke \\ Rasco Hartig-Perschke \\ Institute of Technology and Society, Hamburg University of Technology
}

\begin{abstract}
Election campaigns are catalysts for new forms of political communication. They are a field of experimentation for new techniques and technologies to reach target groups and influence voters. This article explores how weblogs were used in the 2005 Bundestag election campaign in Germany, examining their effect on the mediatized political field. It is based on an empirical analysis of 317 campaign weblogs. Building on mediatization theory and research on campaign weblogs in other countries, weblog usage is examined along the dimensions of activity, interactivity, and connectedness. The results of the study indicate that weblog communication largely follows the dominant logic of mass media. But weblogs also offer forms of communication that allow political actors to bypass established media practices. Although the results are limited by the fact that the political blogosphere in Germany is still under construction, they reveal the potential of weblogs to enrich campaigns.
\end{abstract}

Keywords: Weblogs; campaign; political communication; election; Germany; network analysis

$\bar{Q}$ ection campaigns are an extreme form of political communication. During these periods, the mass media and the electorate devote more attention to the statements of politicians and their parties than at any other time. The stakes are high, indeed; elections are at the core of the political process: the allocation of political power. Because of their importance, campaigns can act as catalysts for new forms of political communication.

This article examines how campaign communication is being changed by a new technological medium: weblogs. By offering easy-to-use content-management software and an attractive presentation, weblogs have revolutionized the way information is distributed on the Internet. In contrast to traditional mass media, weblogs support the interaction of authors-bloggers - with their readers by offering services to comment on articles (socalled "blog posts"). Furthermore, they support the interaction with other bloggers by facilitating hyperlinking to other blogs and blog posts. The totality of weblogs, the "blogosphere," today forms a new communicative space on the Internet.

Although research in political communication has shown that changes in communication technology strongly influence campaigns (Mancini \& Swanson, 1996; Schulz, Zeh, \& Quiring, 2005), little is known about the effects of weblogs yet. On one hand, authors view weblogs as an alternative channel for the distribution of information as well as a mobilization tool due to their ability to spread news very quickly (Ito, 2004; Kahn \& Kellner, 2004).

Authors' Note: The authors would like to thank Björn Greve, Jan Hildebrandt, Judith Muster, Marco Schmitt, and Dr. Klaus Stein for their assistance in conducting the empirical research. 
Bloggers are seen as a "fifth power" that increasingly occupies the control function of the mass media (Gillmor, 2004; Himmelsbach, 2005), contrasting established news values with a more personal, direct, and often location-specific style of reporting. Blogs can be a tool for opinion formation, as they are said to influence agenda setting and framing processes (Drezner \& Farrell, 2004).

On the other hand, hyperlinking on weblogs might foster political fragmentation by connecting only like-minded bloggers, who, as a consequence, avoid dealing with diverging views (Howard, 2005). Blogs are said to destroy the reflective quality of public political communication by letting anybody share their more or less concise thoughts. Blogs are also expected to worsen the inequality of voices in the public sphere by supporting a star culture with few prominent authors (so-called "A-listers") and a large number of unknown bloggers (Shirky, 2003).

This article tries to further the state of research by empirically analyzing political communication with weblogs in the campaign for the German Bundestag election in 2005. Starting from mediatization theory (section two), it explores how the logic of the mediatized political field collides with the logic of the weblogging culture in the campaign blogosphere. In section three, we introduce our research methodology and provide information about the study case. Section four discusses the empirical results and section five presents the conclusions.

\section{Background}

\section{Mediatized Politics}

Research on political communication and, specifically, on campaigns has yielded evidence of a fundamental change of political practices as an effect of mass media's evolution. This process is described analytically by mediatization theory (see Mazzoleni \& Schulz, 1999). According to this theory, "big media" follow their own logic of presenting news to their audiences. For example, research on news values and gatekeeping (Bennett, 2004) has shown that some forms of information have a better chance of being presented than others. Driven by the need to get attention from recipients, the mass media are said to focus on events like political scandals (in contrast to long-term political processes), on surprising and conflict-laden content (instead of discourse and argumentation), and on prominent individuals (in contrast to newcomers and bystanders).

The theory of gatekeeping explains how this logic actually shapes the media field, emphasizing the role of institutionalized practices and their reproduction (Bennett, 2004). With the increase in media usage — especially television — the political field had to adapt its procedures and preferences to comply with this "media logic" (Altheide \& Snow, 1979). The political field turned into a "media democracy," a novel regime in which media logic increasingly determines the political process (Meyer, 2002).

One important question in this theoretical framework is the role technology plays in the process of mediatization. As Bennett (2004) demonstrates in his analysis of gatekeeping, the affordances of a new technology lead to new practices of usage and to new formats of presentation. These new formats affect the media logic and, according to mediatization theory, the whole field of political communication (Bennett, 2004, p. 301f.). This model assigns 
technology an important part in the process of mediatization, but one that is played through interaction with institutionalization and reproduction.

Our study on the effects of weblogs on campaign communication starts from mediatization theory's assumption that the political and media fields together have shaped the logic of today's media democracies. We then ask how weblogs, as a new technologically enabled genre, change campaign communication. Building on the role of technology in the theory of mediatization, we first explore the logic of weblogs. Our research question is how this logic will interact with the logic of mediatized politics. Will one of these logics dominate the forms of communication? Will weblogs actually change campaigning or will they merely reinforce the structures of mass-mediatized campaigns?

\section{Blogging Practices}

To regard weblogs as merely a new technology would discount the Internet as a social phenomenon. Rather, the whole range of weblog culture-from production to reception of information-has to be considered when analyzing the consequences of weblogs. To describe the logic of blogging, we can determine the characteristics of blogging practices (i.e., the "shared routines and expectations that emerge within . . groups of people who use social software" [Schmidt, 2007, p. 34]). We identify four dimensions of weblog use (based on Schmidt \& Wilbers, 2006): (a) the activity of blogging (who posts and to what extent?), (b) the interactivity between authors and readers (feedback received on blog posts), (c) the connectedness of weblogs with the blogosphere by means of blogrolls-lists of hyperlinks to other weblogs - and (d) the authenticity of the bloggers' expression (i.e., a personal, subjective style). ${ }^{1}$

According to a survey of German weblog users (Schmidt \& Wilbers, 2006), weblogs are expected to be updated daily or at least several times a week. Weblog readers expect to be able to comment, though in practice, few posts are commented on. About half of the bloggers consider blogrolls typical elements of a weblog, and a slight majority has a blogroll. This combination of blogging routines and users' expectations shapes a certain practice that establishes a new format of public expression. This format, in turn, follows its own logic: It rewards active involvement in web publishing, orientation toward dialogue, and efforts to establish lasting social relations. Our hypothesis is that this blogging logic overrides the dominant logic of media democracies in shaping campaign communication.

\section{Weblogs in Election Campaigns-Literature Review}

The 2004 U.S. presidential campaign is often cited as a reference point for the political impact of weblogs and even as "a breakout year for the role of the Internet in politics" (Rainie, Cornfield, \& Horrigan, 2005, p. i). Howard Dean demonstrated how such a tool could be used to mobilize supporters and funding, although his candidacy was not successful in the end (Kerbel \& Bloom, 2005). During the campaign, weblogs were used intensively as a source of information and for the purpose of political debate. Weblogs were often cited in the mass media and even influenced their agenda (Cornfield, Carson, Kalis, \& Simon, 2005).

In the past few years, campaign blogging has become an international trend, at least in Western democracies. Studies have examined campaign blogging in the 2004 U.S. presidential 
election (Ackland, 2005; Adamic \& Glance, 2005; Cornfield et al., 2005; Hargittai, Gallo, \& Kane, in press; Kerbel \& Bloom, 2005; Lawson-Borders \& Kirk, 2005; Rainie et al., 2005), the 2005 U.K. general election (Auty, 2005; Coleman \& Ward, 2005; Jackson, 2006; Stanyer, 2006), the 2005 Danish parliamentary election (Klastrup \& Pedersen, 2007), the 2005 New Zealand general election (Hopkins \& Matheson, 2005), and the 2005 German Bundestag election (Abold \& Heltsche, 2006; Ott, 2006). The recent French election has also demonstrated the sustained use of weblogs as a campaign instrument (Arnold, 2007).

These studies show that blogging is widespread among candidates, partisans, and campaign observers. Most of them document that blogs help new actors enter the public sphere, making their voices heard (Coleman \& Ward, 2005; Hopkins \& Matheson, 2005; Klastrup \& Pedersen, 2007; Rainie et al., 2005; Stanyer, 2006). These new actors do not take new political positions, but add new information and viewpoints to the debate (Stanyer, 2006), as the investigations on military service of presidential candidates in the United States showed (Rainie et al., 2005). On the other hand, many politicians use weblogs as mere soapboxes for self-marketing, as the 2005 U.K. election showed (Coleman \& Ward, 2005). These results match the view of German weblog readers, who perceived weblogs as an alternative source of information but were disappointed by most politicians' blogs (Abold \& Heltsche, 2006).

The public reception of weblogs is generally assessed as marginal. According to a survey by the Pew Internet \& American Life Project, only 5\% of the American population says that they used weblogs at least sometimes during the campaign (Rainie et al., 2005). Lawson-Borders and Kirk (2005) also note that the actual impact of blogs on the election has been small. This is even more evident in other countries, where the blogging culture is not as widespread as in the United States. In the United Kingdom, no less than 312 blogs reported about the election (Stanyer, 2006), but the wider public, by and large, did not take any notice (Coleman \& Ward, 2005; Jackson, 2006). The same holds true in New Zealand (Hopkins \& Matheson, 2005).

Several authors have studied the connectedness of weblogs. This research is driven by the thesis of Sunstein (2001) and others that discourse on the Internet tends to attract like-minded participants. As a result, separate arenas emerge, which are each ideologically homogeneous. In the blogosphere, such clusters are apparent from the link pattern among weblogs.

In their study on the 2004 U.S. presidential election, Cornfield et al. (2005) do not find a clustering of blogs along ideological divisions of liberals versus conservatives. This finding contrasts with those of Adamic and Glance (2005), who studied the linking behavior of more than 1,400 political U.S. weblogs with a conservative or liberal orientation. They diagnose an "unmistakable division between the liberal and conservative political (blogo)spheres" (p. 4), that is also evident in a more in-depth analysis of 40 of the most popular political blogs. Their findings are corroborated by Ackland (2005), who studied the same sample of 40 blogs, though with a different methodology. Both studies are based on data collected after the 2004 U.S. presidential election.

Hargittai and her colleagues (in press) also investigated the fragmentation of the political blogosphere and arrive at a more nuanced picture. Whereas blogroll linking indeed follows the "friend or foe" scheme, blog posts contain surprisingly many cross-ideological links. The authors conclude that there is a tendency in political weblogs to link to others who are like-minded but find "no support for the claim that IT will lead to increasingly fragmented discourse online" (Hargittai et al., in press, p. 24). 
This moderate position is also found in studies on campaign weblogs in Germany, the United Kingdom, and Denmark. In the 2005 Bundestag campaign, Ott (2006) notices that blogrolls primarily linked to their own party's blogs. Stanyer (2006) observed a certain degree of partisan skewing within blogrolls in the United Kingdom, particularly among the left-wing blogs and among Members of Parliament (MPs) and candidates. However, the partisan skewing was not as strong as that reported by Adamic and Glance (2005) for the United States. In Denmark, only a few campaign blogs linked at all to others. Klastrup and Pedersen (2007) conclude that politicians adopted weblogs as a decentralized campaign tool but did not contribute to the spread of political debate.

Finally, a number of studies directly compare blogging activity to the media's coverage of the campaigns. The general picture is that weblogs have had only a small role to play in the campaign but filled a niche within the mediascape (see Rainie et al., 2005, for the United States in 2004; Stanyer, 2006, for the United Kingdom in 2005; Hopkins \& Matheson, 2005, for New Zealand in 2005).

We can summarize our literature review as follows: Along the dimension of activity, we find that weblogs allow new actors with new views to participate in the campaign discourse, filling a niche within the mediascape. This finding suggests that the logic of blogging affects campaign communication. But along the dimensions of interactivity and of connectedness, weblogs seem to follow the logic of the mediatized political field. They are subject to the same economic logic that directs attention to well-known actors. And, if not deepening the cleavages, they mirror the fragmentation of the political field. This similarity of blogging practices to the media-political logic makes sense given that, at least in the United States, many campaign bloggers were journalists (Lawson-Borders \& Kirk, 2005), and many journalists use blogs as a guide to the sources of information on the Internet (Cornfield et al., 2005).

\section{Data and Method}

Our study seeks to systematically and empirically assess the impact of weblogs on the 2005 German Bundestag campaign. The campaign blogosphere is our object of study, defined as all weblogs focusing on issues related to the election in the past 2 months of the campaign. We confine our empirical observation to the campaign blogosphere because it represents the intersection of the media-political field and blogging culture.

This case study is explorative in nature because of the novelty of campaign blogging in Germany. It is guided by the analytical dimensions of activity, interactivity, and connectedness, as identified in the previous section. In contrast to other studies of the Bundestag campaign, we do not limit our observation to blogs of political actors in the narrower sense (i.e., candidates and parties) but consider all campaign blogs. In our sampling strategy, we also follow explicit methodological guidelines and do not employ online surveys, as their results are often biased when used in campaign research, reaching primarily "campaign junkies" (Schoen \& Faas, 2005, p. 328).

We first analyze blogging activity during the campaign focusing on the characteristics of blog authors, quantity of postings, and weblog age. We then investigate the level of feedback candidate weblogs receive from readers (i.e., their degree of interactivity). The independent 
variables are the prominence of the author and the type of service hosting the weblog. Finally, we analyze the connectedness of weblogs by means of blogroll links to determine how similar the blogosphere's structure is to the political field.

At the time of the campaign, the blogging culture in Germany grew slowly. The political blogosphere was still "under construction" (Albrecht, Lübcke, Perschke, \& Schmitt, 2005). Lacking an adequate index, we employed a combination of sampling strategies, including search engines, pertinent lists published on dedicated web sites, as well as snowball sampling techniques to collect as many campaign blogs as possible (see Albrecht et al., 2005 , for further details on the sampling process). Only campaign web sites with entries in chronologically reverse order and at least two of the following features were chosen for the sample: They are explicitly characterized as a weblog or online diary, they link to other weblogs in their blogrolls or posts, and they allow readers to comment on their posts directly on the site.

This process yielded a sample of 317 weblogs. For each weblog, blogroll links were archived every 2 weeks during the last 2 months of the campaign. The content of the weblogs was surveyed once in the week following the election and all blog posts were saved for further analysis. Weblogs that were completely deleted by their owners immediately after the election are treated as "missing."

\section{Context and Electoral System of the Bundestag Election}

Before discussing our results, we briefly sketch the German electoral system and the context of the 2005 Bundestag election. Although German campaigns are said to mirror the presidential campaigns in the United States (Korte, 2006), the electoral system differs considerably from the American model (see Drück, 2004, and Wüst, Schmitt, Gschwend, \& Zittel, 2006). It is characterized by mixed-member proportional representation and a multiparty system with strong party organizations. The role of candidates in the campaign is to lend a face to the campaign and to fight for votes locally. Members of the Bundestag are elected either through their party's list or directly within their constituency.

The 2005 Bundestag election was historically peculiar for several reasons (cf. Wüst \& Roth, 2006). Chancellor Gerhard Schröder called an early election after his party had lost the election in North Rhine-Westphalia in May 2005. The legal problems of this decision occupied the institutions until less than 1 month before Election Day on September 18, 2005 , and the campaign phase was short and intense. The voters basically had to choose between two options: the incumbent Social Democratic Party (SPD) and Green Party coalition, and the challenging Christian Democrats (CDU/CSU) and Liberal Democrats (FDP) coalition. The governing coalition scored low in polls compared to their opponents, reversing the traditional positions of incumbent and challenger, and had to run a campaign to prove they were still able to lead the country. A third competitor, the Left Party-formed by the EastGerman Party of Democratic Socialism and West-German WASG (Wahlalternative Arbeit und soziale Gerechtigkeit, Election Alternative for Work and Social Justice)—represented a new force on the left that threatened to take votes from the SPD (Roberts, 2006).

The result of the election was also historically significant, as neither of the two opposing coalitions succeeded in forming the government. Instead, SPD and CDU/CSU were forced to build a grand coalition, with the latter taking the lead under the new chancellor, 
Angela Merkel. Analysts expect this election to have fundamental consequences for the German party system (Roberts, 2006; Wüst \& Roth, 2006).

\section{Empirical Results}

\section{Overview of the Campaign Blogosphere}

Although online campaigning in Germany is sometimes regarded as a mere supplement to or mirror of the "real world" campaign (Bieber, 2005), parties and politicians are extending their web presence and experimenting with new forms of communication (Hebecker, 2002; Schweitzer, 2005, p. 345). The use of weblogs in the 2005 campaign is a case in point. Against the background of the lively debate about weblogs in the U.S. presidential campaign, several German politicians and strategists were eager to use this new medium (Lianos \& Schröder, 2005). With a total of about 60,000 to 100,000 weblogs in Germany as of the summer of 2005 (Sixtus, 2005) and the potential to reach 64\% of the German electorate via the Internet (Forschungsgruppe Wahlen Online, 2005), the blogosphere promised to resonate well with modern campaigning.

Between the end of May and the beginning of September, the number of weblogs covering the election grew steadily, as Figure 1 shows. The fastest growth was observed after July 21 st, when president Horst Köhler decided that the election would actually be held. In the last days of the campaign, only a few journalists set up new blogs to cover the final phase. About a quarter of the weblogs in our sample were established before the election was called. Some of the blogging ambitions were not realized: 19 weblogs (6\%) were set up but no posts published.

With regard to the actors involved in blogging, the sample is structured as follows: A total of 6 weblogs were run by specialists (e.g., design agencies, political communication experts) who did not take an active part in the campaign, 15 blogs were written by journalists, and 93 by politically interested citizens, 30 of whom supported one or another party. Furthermore, we found that 76 bloggers belonged to party organizations, 83 were candidates for a seat in parliament, and 38 were existing Members of Parliament. Finally, 6 blogs were written by a collective of laypeople and politicians - both incumbents and challengers.

The number of laypeople in comparison to journalists and political professionals is remarkably high (also compared to the 2004 U.S. election-cf. Lawson-Borders \& Kirk, 2005). This suggests that weblogs in the Bundestag campaign indeed helped new actors to enter the public sphere on an equal footing with established politicians-especially politically interested citizens and less prominent politicians. The blogosphere appears more diversified than the set of actors that appears in traditional news media.

The formats of the campaign blogs in our sample are further evidence of such diversity. Journalists used their weblogs to cover local campaigning. Citizens commented on the campaign and analyzed the strategies of the different parties from a personal perspective. Another weblog format consists of several authors with opposing political standpoints, a kind of ongoing online panel discussion. These sites were initiated by politically independent actors who were generally interested in promoting weblogging. However, the largest part of the sample consists of weblogs written by politicians. 
Figure 1

Growth of the Campaign Blogosphere in 2005

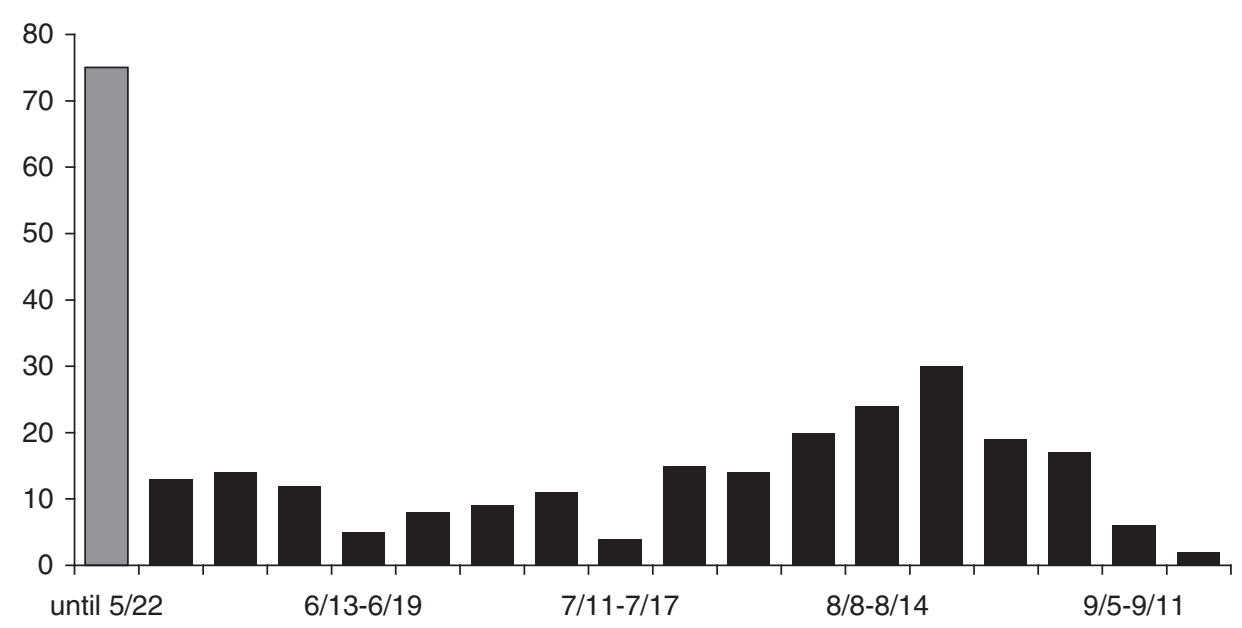

Note: Bars represent the number of new blogs per week.

The campaign blogosphere covered the entire range of the political spectrum (see Figure 2). The plurality of blogs supported the SPD (81 weblogs, 26\%), whereas the CDU/CSU and Left Party only had a small number of partisan blogs (16 and 18 blogs, representing 5\% and $6 \%$, respectively). Two small parties, the FDP and the Greens, were in between, with 39 $(12 \%)$ and $48(15 \%)$ blogs, respectively, supporting them. The sample contains only one blog supporting the far right National Democratic Party. As we assume a certain amount of covert online activity in this part of the political spectrum, this might underestimate the number of blogs supporting the far right.

The parties' blogging strategies varied substantially. The weblogs of the CDU/CSU were predominantly written by politicians themselves. Only the CSU had an official blog ("Blog for Berlin"), whereas the weblog "CDUnion" was written by independent partisans. The SPD, in contrast, offered a broad range of weblogs, from several central campaign blogs, to rapid-response and negative campaigning blogs, to individual blogs hosted on the party's own blogging platform. The SPD purportedly abstained from controlling whether these hosted blogs conformed with its campaign strategy (cf. Lianos \& Schröder, 2005).

The smaller parties fit in between these strategies, with a combination of several personal weblogs and a few official weblogs, such as weblogs of the parties' youth organizations (Greens, FDP) and weblogs to raise money for the campaign (FDP). The overrepresentation of the small parties in the blogosphere (except for the Left Party) marks another difference from the media-political field, where the big parties have a stronger presence.

\section{A Tool for Campaigning or for Sustained Dialogue?}

We wanted to find out whether campaign blogs were mainly used for the short period of the campaign, characteristic of media democracy's focus on events, or rather as a tool for building up and managing long-term social relations, characteristic of the blogging culture (Schmidt, 
Figure 2

\section{Campaign Weblogs According to Party Affiliation and Orientation (absolute frequencies in parentheses)}

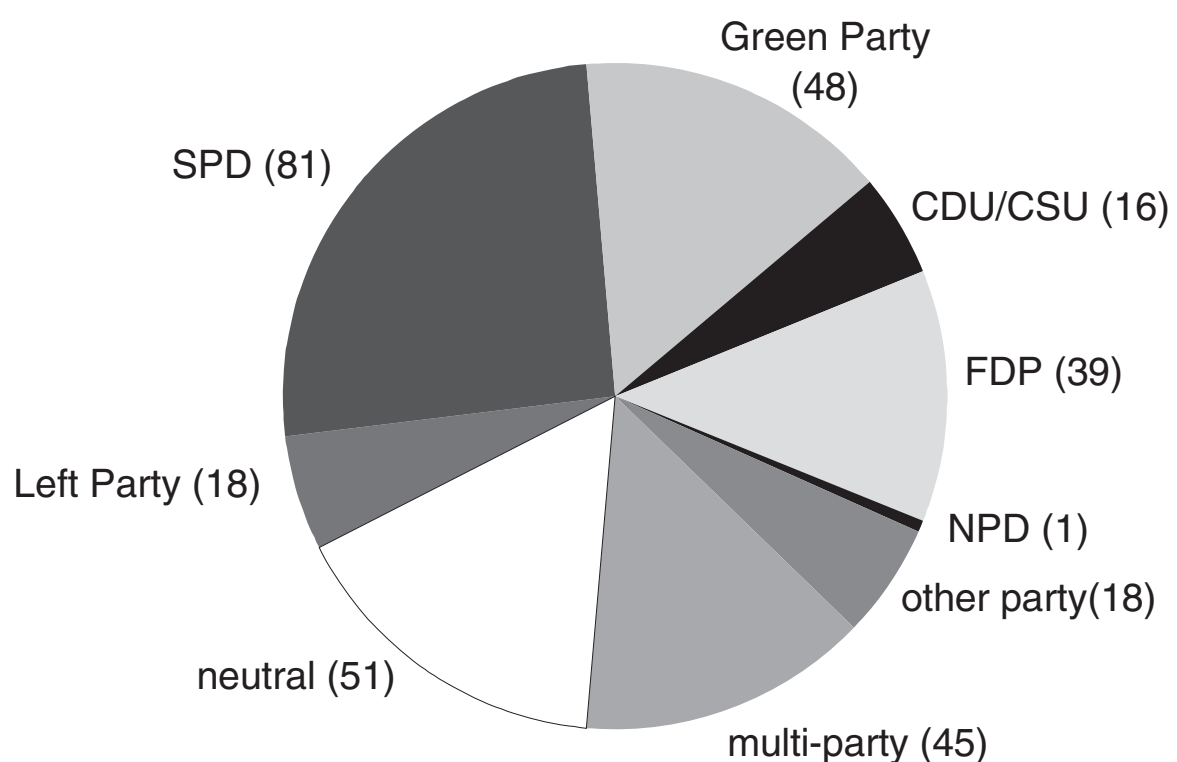

2007). To answer this question, we revisited each weblog on May 22, 2006, 1 year after the election had been called. A total of 93 weblogs were still active (at least 1 new posting in the last 4 weeks). A total of 65 bloggers had not posted anything since the election and 43 blogs were offline. A remaining 61 weblogs stopped their activity before the end of 2005.

Looking at the weblogs of candidates and MPs, only 15 out of 121 (9 candidates and 6 MPs) were kept up to date through May 2006. Therefore, although many blogs were created as a part of the 2005 campaign in Germany, most of them were used as a campaign tool, and this holds especially for weblogs of parties and politicians.

Only a few political actors attempted to establish a long-term web presence with their weblogs. Similar to the 2005 British elections, weblogs had once again only become the "latest and safest' media-friendly tool used by those who wanted to give the impression of being comfortable with getting up-close-and-personal with the public" (Ferguson, 2005, p. 33). Nevertheless, the 15 weblogs still active show that at least some politicians are exploring the potential of political blogs, trying to establish sustained dialogue with their constituency.

\section{Politician's Blogs: Just Active or Interactive?}

In the following section, we will have a closer look at how politicians used their weblogs and how their activity was perceived by Internet users. Politicians are the largest subgroup in our sample. ${ }^{2}$ How did weblogging influence their style of political communication? More specifically, we are interested in how they complied with the blog readers' expectations, and in how their commitment and their position in the political field influenced the feedback they received. 


\section{Table 1}

\section{Activity and Interactivity of MPs' and Candidates' Weblogs, Categorized by Party Affiliation, Actor Type, and (for the 10 highest ranked weblogs) Blog Hoster}

\begin{tabular}{lclr}
\hline Activity (number of posts) & Mean & Interactivity (comments per post) & Mean \\
\hline Party Affiliation & & Party Affiliation & \\
Left party & 25.2 & SPD & 8.9 \\
Other party & 20.1 & CDU/CSU & 7.9 \\
Green party & 13.2 & FDP & 4.7 \\
SPD & 12.4 & Green party & 4.7 \\
FDP & 11.4 & Left party \\
CDU/CSU & 8.4 & Other party & 2.8 \\
Actor Type & & Actor Type & 1.3 \\
MPs & 14.6 & MPs & 7.0 \\
Candidates & 14.5 & Candidates & 3.7 \\
Individual Candidates & & Individual Candidates \\
Dirk Schneider, Indep. (M) & $107^{*}$ & Andrea Nahles, SPD (F) & \\
Stefan Liebich, Left (M) & $96 *$ & Oswald Metzger, Green (F) & 67.4 \\
Helmut Gobsch, Indep. (W) & $76^{*}$ & Katherina Reiche, CDU (A) \\
Martin Hohmann, Indep. (M) & $59 *$ & Niels Annen, SPD (A) & 44.9 \\
Anna Lührmann, Green (M) & $41^{*}$ & Hildegard Müller, CDU (F) & 24.3 \\
Gesine Lötzsch, Left (M) & $34^{*}$ & Marco Buschmann, FDP (W) & 22.5 \\
Cornelia Pieper, FDP (W) & $33^{*}$ & K. Göring-Eckardt, Green (A) & 16.6 \\
Petra Pau, Left (A) & $31^{*}$ & Ulrich Kelber, SPD (M) & 15.1 \\
Gerhard Schick, Green (M) & $29 *$ & Petra Pau, Left (A) & 13.8 \\
Sebastian Weigle, SPD (M) & $29 *$ & Hermann-Otto Solms, FDP (A) & 10.7 \\
Summary Measures & & Summary Measures & 10.3 \\
Overall mean & 14.6 & Overall mean & 9.1 \\
Overall median & 9 & Overall median & 4.8 \\
& & & 2.3 \\
\hline
\end{tabular}

Note: MP = Member of Parliament; SPD = Social Democratic Party; FDP = Liberal Democrats; CDU/CSU = Christian Democrats. Blog Hoster: A = AOL, F = Focus Online, $\mathrm{W}=$ wahl.de, $\mathrm{M}=$ miscellaneous/self-designed. $*=$ absolute value.

The average activity on candidate weblogs was 14.5 posts during the last 4 weeks of the campaign. There was a median of 9 posts and the distribution of activity was right-skewed. Only seven weblogs (7\% of all politicians' blogs) had at least one post per day.

Activity and interactivity are not correlated in our sample: Bloggers who write frequently do not earn a higher amount of responses. Furthermore, readers make use of their ability to comment on blog posts to varying degrees, depending on the prominence of the author or the weblog.

Among the 10 most active bloggers, most are taking a back seat in their party or are independent candidates (see Table 1). But with exception of Petra Pau, a well-known left politician - they received less feedback from their readers than average, with four of the most active bloggers receiving the fewest average responses per post.

In contrast, among the bloggers who received the largest amount of feedback, the most important determinants of response seem to be the visibility and prominence of the weblog or its author. A total of 8 of the 10 weblogs most frequently commented on were hosted by Focus Online and America Online (AOL), among the most visited web portals in Germany (with a total of 11 Focus Online and AOL blogs in the sample). These portals were able to 
draw a lot of traffic to their weblogs. All of these 8 weblogs were written by prominent politicians. Although this result is not surprising, the two exceptions are interesting because they show that some actors succeeded in bypassing the dominant logic. Their weblogs were hosted on their own server or on "wahl.de," a special hosting service for politicians.

These findings indicate that the news values and gatekeepers of the mass media are of considerable importance for weblogs in this field. The prominence of politicians and the degree of popularity of gatekeepers such as news portals affect their weblogs' visibility on the Internet, thus drawing the attention of potential readers. As to the two exceptions to this, the bloggers tried to meet the expectations of weblog readers, keeping their weblogs up to date and interacting with their audience. This indicates the potential of weblogs to cross mass media's logic of attention, which dominates the political field both offline and online.

\section{Network Structure of the Bundestag Campaign Blogosphere}

Interestingly, bloggers' prominence was an attractor for comments as well as for blogroll hyperlinks. Blogs had an average of 8.7 hyperlinks, with a median of 2 . A majority of the blogs $(187,59 \%)$ had no blogroll links to other campaign blogs. Most of the remaining blogs referred to just a few others: $23.2 \%$ contained 1 to 6 links, $11.3 \%$ had 7 to 15 links, and a mere 5.5\% had more than 15 links. The longest blogroll in our sample pointed to 73 other blogs. Links within the blogrolls were set (a) to ideologically related weblogs (e.g., to weblogs of the own party), (b) according to the personal interests of the owner, or (c) regardless of their political orientation. In some cases, blog providers set links automatically. For example, Focus Online weblogs always contained links to other Focus Online blogs but did not refer to blogs hosted by other providers.

By following these links, one is able to trace the network structure of the Bundestag campaign blogosphere (see Marlow, 2004, for a similar approach). A total of 195 weblogs are part of the interconnected network of campaign blogs. ${ }^{3}$ Of these, 113 were mutually connected to each other, 11 were only sending out links, and 71 were only receiving links. Another 116 weblogs neither sent nor received links.

The density of this network (the relation of actual vs. possible links) is $1.12 \%$, which means that 1,081 links out of 96,410 possible were established between the 311 blogs. This amount of realized connections indicates a complex and heterogeneously structured network. The distribution of blogroll links points to a widespread network with a large, sparsely connected periphery and a strongly connected core. Figure 3 shows the structure of the network.

Differences between central and peripheral blogs can be described in detail with the so-called "indegree centrality," an index that counts the number of links pointing to a blog. The more incoming links a blog gets, the more likely it is that it will be found by a reader. The centrality of a weblog can be interpreted as the amount of attention it gets within the blogosphere. Again, the distribution of indegrees across weblogs was highly skewed. Among all the blogs, $127(40.8 \%)$ did not receive any links, 152 received between 1 and 10 links and the remaining 32 blogs received between 11 and 30 links. Focusing on the subgroup of blogs receiving links, there was an average of 5.9 links and a median of 3.5 links for each blog.

On one hand, weblogs from well-known politicians and weblogs hosted by large web portals were able to gain attention-matching the results we found for interactivity. On the other hand, three independent campaign blogs from bloggers with a long-established 
Figure 3

\section{Blogroll Network of Campaign Weblogs, Categorized According to Party Affiliation (spring-embedded layout)}

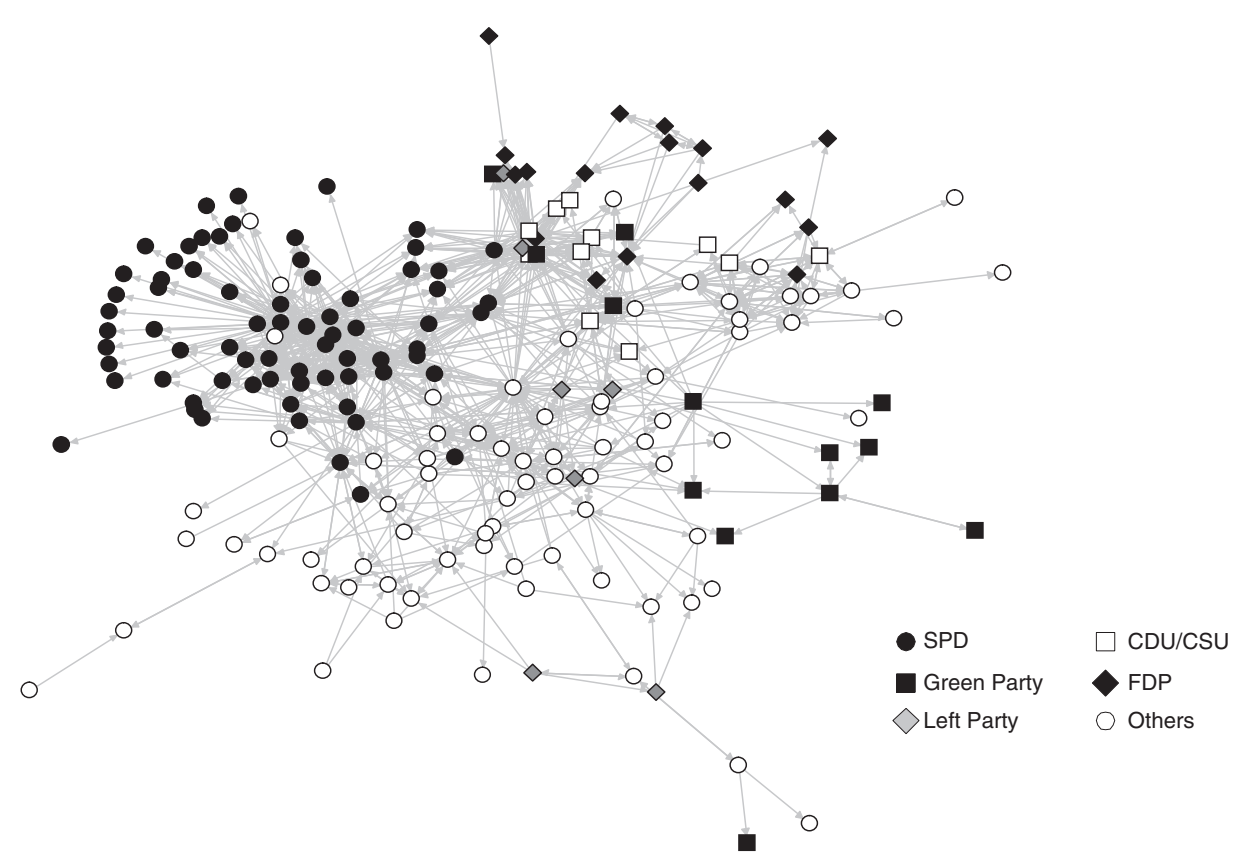

reputation also attracted much attention. They started at an early stage of the election campaign (two of them within hours of the call), and thus had time to build up a central standing.

Our analysis shows that the logic of the mass media dominates the blogosphere by mainly drawing attention to prominent actors. If we prescind from the individual blogger, the question arises whether the structure of the political field is reflected in the structure of the blogosphere as well. Hence, we analyze the blogroll network with regard to parties and their linkages. Table 2 shows the result of the network's segregation into blocks according to party affiliation. The relations between blocks were analyzed using a density matrix (see Wasserman \& Faust, 1994). Each cell represents the amount of connections between two groups of weblogs relative to the amount of possible connections. This method simultaneously takes into account the respective sizes of the weblog groups sending and receiving links.

As we can see from Table 2, no single party cut off from the others completely, though the SPD refrained the most from cross-party networking. Neither did the blogrolls mirror the traditional political camps: The would-be coalition of CDU/CSU and FDP entertained close links to each other, but there were also a number of links between the CDU/CSU and the rivaling coalition of SPD and Greens.

Thus we have to reject the assumption of a clear ideological division for the 2005 Bundestag campaign blogosphere. For the United States, Adamic and Glance (2005) recorded $91 \%$ of links directed to blogs within the same political camp. In contrast, only $77 \%$ of the links of SPD and Green blogs were directed to their own camp, and just $50 \%$ 
Table 2

Density Matrix of Blogroll Links According to Party Affiliation (showing percentages)

\begin{tabular}{lrrrrrrr}
\hline Block Name & $n$ & CDU/CSU & FDP & SPD & Green & Left & Other \\
\hline CDU/CSU & 11 & $\mathbf{1 6 . 4}$ & $\mathbf{9 . 1}$ & 2.3 & $\mathbf{4 . 9}$ & $\mathbf{3 . 9}$ & 2.8 \\
FDP & 17 & 3.2 & $\mathbf{1 1 . 8}$ & 0.7 & 1.8 & 0.8 & 0.7 \\
SPD & 71 & 1.7 & 0.6 & $\mathbf{7 . 9}$ & 0.4 & 0.6 & 1.6 \\
Green & 13 & 3.5 & 3.2 & 1.0 & $\mathbf{1 0 . 9}$ & 1.1 & 0.5 \\
Left & 7 & $\mathbf{7 . 8}$ & $\mathbf{5 . 9}$ & 1.8 & $\mathbf{5 . 5}$ & $\mathbf{7 . 1}$ & 3.6 \\
Other Blogs & 76 & 3.2 & 1.8 & 0.8 & 1.5 & 1.5 & $\mathbf{3 . 9}$ \\
\hline
\end{tabular}

Note: Blocks with weblogs sending links out are listed in the rows, those with weblogs receiving links in columns. Density scores that are above average are printed in bold. The mean density across all blocks is $3.8 \%$; the overall density of the network of weblogs with blogrolls is $2.9 \%$. CDU/CSU $=$ Christian Democrats; FDP $=$ Liberal Democrats; SPD = Social Democratic Party.

among CDU/CSU and FDP weblogs. Nevertheless, the affiliation with a political group does have an important influence on the network's structure. Table 2 shows higher density values along the diagonal, which means that links between blogs belonging to the same group are more frequent than links to others. In addition, we observe high density values between the CDU/CSU and the FDP, whereas the SPD and Greens keep more of a distance. Both former governmental coalition partners were loosely connected by blogroll links, thus demonstrating self-reliance and an individual profile in the online campaign, which mirrors their offline strategy (Niedermayer, in press). The Left Party's position on the network is very similar to its political isolation (Roberts, 2006), too. Its blogs are linked to various other groups but receive only a few incoming links. Thus, on closer examination, we find that the Bundestag campaign blogosphere indeed mirrors the structure of the political field.

To sum up, blogroll links draw an instructive picture of the structure of the blogosphere. Due to the fact that a large proportion of blogs did not provide a blogroll, the overall network of blogs was only sparsely connected. The network is characterized by a center-periphery structure, and only weblogs in the center exchanged links to a large degree. The network also showed that links are directed primarily to weblogs of the same party. Furthermore, links were established primarily to prominent blogs within the blogosphere, depending on the prominence of the blog's platform, the recognition of the author, and the time the blog was online.

\section{Conclusion}

Our case study shows that weblogs played an important role in the Bundestag campaign as far as we consider their active usage. All major parties and many candidates used this new mode of communication, though only a few attracted much attention. Campaign weblogs were found to have a limited reach, at least with regard to the number of comments they provoke. Thus, our study confirms the results of previous studies on campaign weblogging that weblogs fill a niche in campaign communication.

Furthermore, we wanted to find out whether this niche position corresponds to a specific form of communication, a specific "weblog logic" contrasting with the "media logic" 
documented in studies of political communication. Our results led to different answers for the three dimensions we have distinguished. Along the dimension of activity, we found mixed evidence. On one hand, weblogs allow new actors to engage in campaign communication. This is in contrast to the media logic of gatekeepers limiting the scope of actors that appear on the public stage. On the other hand, weblogs were mainly used as a campaign instrument with a short-term perspective, which is in line with the time horizon of mediatized politics.

Along the dimension of interactivity, the results clearly indicate that the campaign blogosphere has adopted the media logic. Weblogs of prominent actors or weblogs hosted by well-known online portals receive the largest share of attention independent of their authors' activity. We confirmed this result with two different measures of attention, the number of comments per post and the indegree centrality score. Only a few weblogs with other characteristics were able to receive much attention from readers, indicating that sincerity and long duration of blogging can lead to higher levels of interaction with readers.

Finally, along the dimension of connectedness, the hyperlink structure of the campaign blogosphere resembled very much the ideological structure of the political field in general. This result supports the view of weblogs as a mirror of the offline world. It rejects both the skeptical thesis implying weblogs worsen political fragmentation and the optimistic thesis implying weblogs foster dialogue across ideological divides.

In our interpretation, these results are an indicator that the logic of mediatized politics is strongly affecting weblog communication in the campaign. But under certain circumstances, the distinctive logic of weblogs interferes with this dominant logic, allowing actors from the periphery of the political field to gain a more prominent position. Based on our explorative study, we suggest that the decisive condition for this to happen is that the blogger conforms with the cultural norms of blogging. This includes to post regularly and with a long-term perspective to build social relationships, to engage in discussions with the readers who comment, and to connect to other bloggers by hyperlinking. Further studies are required to confirm this tentative conclusion.

As an advice to political actors with small reputations, we recommend that they try to play against the rules of the mediatized political field. These actors will profit from using weblogs if they adopt established blogging practices and persistently engage in communication with readers and fellow bloggers. At least, such a strategy was evident in the few cases in our study when weblog logic prevailed over media logic and allowed actors to bypass gatekeepers in media and party organizations.

Assuming that campaigns act like a prism in making visible the special features of political communication (Holtz-Bacha 2004, p. 468), our findings are relevant not only for campaigns, but also for the political process more generally. However, the novelty of blogging as a mode of communication limits the generalizability of the results. The field of campaign weblogs was still under construction in Germany at the time of the Bundestag campaign 2005. Observations of the campaigns in the United Kingdom, New Zealand, and Denmark, where weblog diffusion was at a comparable stage, support our findings; with more time and widespread adoption, the practices might come to resemble the pattern found in the United States, where the dominance of media logic was more evident.

To estimate the influence of weblogs for political communication, one has to consider the whole public sphere and not just the political actors. Weblog use will increase the personalization of campaigns and speed up political communication. Politicians who report about their daily life and interact with their readers work against the impression of a disconnected political 
caste (Coenen 2005). Bloggers scrutinizing media reports and campaign information and engaging in political discussions across the blogosphere offer an alternative to highly professionalized campaigns. The impact of weblogs on campaigns, and on political communication more generally, will depend on actual usage once campaign blogging reaches maturity. More comparative and follow-up studies are necessary to make assertions about these future developments.

\section{Notes}

1. The fourth dimension, authenticity, is mentioned only for the sake of completeness. Due to our methodological focus on the weblogs and not on their content, we were not able to investigate this dimension of usage empirically. Thus, we omit this dimension in our analysis.

2. The subsample for this analysis consists of all blog posts and comments on the 121 weblogs of MPs and their challengers (i.e., all candidates) that were published between August 18, 2005, and Election Day (September 18, 2005). Weblogs of 17 candidates were not active during the last month of the campaign, mostly those of relatively unknown politicians. Four weblogs were considered "missing cases" because the content had been deleted immediately after the election, before our observation took place. The remaining 100 active candidate blogs are the basis of our analysis.

3. The analysis refers to the blogroll lists found on the blogs close to Election Day. Six weblogs are treated as missing data because they were observed only in retrospect. The constructed network was binary coded. Multiple links between blogs were excluded, as well as links from blogs that were not part of our sample. We also excluded self-references.

\section{References}

Abold, R., \& Heltsche, M. (2006). Weblogs in political campaigns-the critical success factors. Paper presented at BlogTalk Reloaded, Vienna, Austria. Retrieved February 28, 2007, from http://blogtalk.net/ Main/Papers ?action=download\&upname=Weblogs 20 in $\% 20$ Political $\% 20$ Campaign.$p d f$

Ackland, R. (2005, May). Mapping the U.S. political blogosphere: Are conservative bloggers more prominent? Paper presented at BlogTalk Downunder, Sidney, Australia. Retrieved February 28, 2007, from http://acsr.anu.edu.au/staff/ackland /papers/polblogs.pdf

Adamic, L., \& Glance, N. (2005, May). The political blogosphere and the 2004 U.S. election: Divided they blog. Paper presented at 2nd Annual Workshop on the Weblogging Ecosystem-Aggregation, Analysis and Dynamics, Chiba, Japan. Retrieved February 28, 2007, from http: / /www. blogpulse. com/papers / 2005 /AdamicGlanceBloghtw. pdf

Albrecht, S., Lübcke, M., Perschke, R., \& Schmitt, M. (2005). "Hier entsteht eine neue Internetpräsenz"Weblogs im Bundestagswahlkampf 2005. ["Work in Progress"-Weblogs in the Bundestag Election Campaign 2005] kommunikation@gesellschaft, 6. Retrieved February 28, 2007, from http: / /www. soz .uni-frankfurt.de/K.G/F1_2005_Albrecht_Luebcke_Perschke_Schmitt.pdf

Altheide, D. L., \& Snow, R. P. (1979). Media logic. Beverly Hills, CA: Sage.

Arnold, M. (2007, April 4). Contenders go online with diverse strategies. Financial Times, sect. Europe, p. 7.

Auty, C. (2005). UK elected representatives and their weblogs: First impressions. Aslib Proceedings, 57, 338-355.

Bennett, W. L. (2004). Gatekeeping and press-government relations: A multigated model of news construction. In L. L. Kaid (Ed.), Handbook of political communication research (pp. 283-313). Mahwah, NJ, \& London: Lawrence Erlbaum.

Bieber, C. (2005). TV kills the Internet star. Retrieved February 28, 2007, from http://www . politikdigital.de/edemocracy/wahlkampf/bundestagswahl $05 /$ kommentarbieber050603. shtml

Coenen, C. (2005). Weblogs als Mittel der Kommunikation zwischen Politik und Bürgern-Neue Chancen für die E-Demokratie? [Weblogs as a means of communication between politics and citizens-new chances for e-democracy.] kommunikation@gesellschaft,6. Retrieved February 28, 2007, from http://www.soz. uni-frankfurt.de/K.G/B5_2005_Coenen.pdf 
Coleman, S., \& Ward, S. (Eds.). (2005). Spinning the Web. Online campaigning in the 2005 general election. London: Hansard Society.

Cornfield, M., Carson, J., Kalis, A., \& Simon, E. (2005). Buzz, blogs and beyond. The Internet and the national discourse in the fall of 2004. Retrieved February 28, 2007, from http://www. pewinternet .org/ppt/BUZZ_BLOGS_BEYOND_Final05-16-05.pdf

Drezner, D. W., \& Farrell, H. (2004). The power and politics of blogs. Retrieved February 28, 2007, from http: / /www. danieldrezner.com/research/blogpaperfinal.pdf

Drück, H. (2004). Germany. In B.-P. Lange \& D. Ward (Eds.), The media and elections. A handbook and comparative study (pp. 59-76). Mahwah, NJ, \& London: Lawrence Erlbaum.

Ferguson, R. (2005). Diving into the shallow end. In Hansard Society (Ed.), Spinning the Web. Online campaigning in the 2005 general election (pp. 31-35). London: Hansard Society.

Forschungsgruppe Wahlen Online. (2005). Internet-Strukturdaten. Repräsentative Umfrage-III. Quartal 2005. [Structural data on the Internet. Representative survey, 3rd quarter 2005] Retrieved February 28, 2007, from http: / / www. forschungsgruppe.de/Ergebnisse/Internet-Strukturdaten/ web_III_05.pdf

Gillmor, D. (2004). We the media. Grassroots journalism by the people, for the people. Sebastopol, CA: O'Reilly.

Hargittai, E., Gallo, J., \& Kane, M. (In press). Cross-ideological discussions among a group of conservative and liberal bloggers. In D. W. Drezner \& H. Farrell (Eds.), The political promise of blogging. Ann Arbor: University of Michigan Press.

Hebecker, E. (2002). Experimentieren für den Ernstfall. Der Online-Wahlkampf 2002. [Experimenting for the real thing. The online election campaign 2002.] Aus Politik und Zeitgeschichte, 49-50, 48-54.

Himmelsbach, S. (2005). Blog. The new public forum. In B. Latour \& P. Weibel (Eds.), Making things public. Atmospheres of democracy (pp. 916-921). Cambridge, MA: MIT Press.

Holtz-Bacha, C. (2004). Political communication research abroad: Europe. In L. L. Kaid (Ed.), Handbook of political communication research (pp. 463-477). Mahwah, NJ, \& London: Lawrence Erlbaum.

Hopkins, K., \& Matheson, D. (2005). Blogging the New Zealand election: The impact of new media practices on the old game. Political Science, 57, 93-105.

Howard, P. N. (2005). Deep democracy, thin citizenship: The impact of digital media in political campaign strategy. Annals of the American Academy of Political and Social Science, 597, 153-170.

Ito, J. (2004). Weblogs and emergent democracy, Version 3.2. Retrieved February 28, 2007, from http:// joi.ito.com/static/emergentdemocracy.html

Jackson, N. (2006). Dipping their big toe into the blogosphere. The use of weblogs by the political parties in the 2005 general election. Aslib Proceedings, 58, 292-303.

Kahn, R., \& Kellner, D. (2004). New media and Internet activism: From the "Battle of Seattle" to blogging. New Media \& Society, 6, 87-95.

Kerbel, M. R., \& Bloom, J. D. (2005). Blog for America and civic involvement. The Harvard International Journal of Press/Politics, 10, 3-27.

Klastrup, L., \& Pedersen, P. S. (2007). Blogging for election. The use and function of blogs as communication tool in a Danish Parliament election campaign. In M. Consalvo \& C. Haythornthwaite (Eds.), Internet research annual 2005. Selected papers from the Association of Internet Researchers Conference 2005 (pp. 27-40). New York: Peter Lang.

Korte, K.-R. (2006). Model or deterrence? The United States presidential election campaigns and the Bundestag election campaigns. German Politics, 15, 153-165.

Lawson-Borders, G., \& Kirk, R. (2005). Blogs in campaign communication. American Behavioral Scientist, 49, $548-559$.

Lianos, M., \& Schröder, T. (2005). Kampf im Netz. Roundtable-Gespräch zum Internet-Wahlkampf. [The battle on the Internet. Roundtable talk on the Internet election campaign.] Politik \& Kommunikation, Wahlkampf Special, 2, 22-25.

Mancini, P., \& Swanson, D. L. (1996). Politics, media and modern democracy: Introduction. In D. L. Swanson \& P. Mancini (Eds.), Politics, media and modern democracy. An international study of innovations in electoral campaigning and their consequences (pp. 1-26). Westport, CT, \& London: Praeger.

Marlow, C. (2004, May). Audience, structure and authority in the weblog community. Paper presented at 54th Annual Conference of the International Communication Association, New Orleans, LA. Retrieved February 28, 2007, from http://www. overstated.net/media/ICA2004.pdf 
Mazzoleni, G., \& Schulz, W. (1999). "Mediatization" of politics: A challenge for democracy? Political Communication, 16, 247-261.

Meyer, T. (2002). Media democracy. How the media colonize politics. Cambridge, UK: Polity Press.

Niedermayer, O. (In press). Der Wahlkampf zur Bundestagswahl 2005. [The campaign in the Bundestag election in 2005.] In F. Brettschneider, O. Niedermayer, B. Pfetsch, \& B. Weßels (Eds.), Die Bundestagswahl 2005. Analysen aus Sicht der Wahlforschung, der Kommunikationswissenschaft und der Parteienforschung. Wiesbaden, Germany: VS Verlag für Sozialwissenschaften.

Ott, R. (2006). Weblogs als Medium politischer Kommunikation im Bundestagswahlkampf 2005. [Weblogs as a means of political communication in the Bundestag Election Campaign 2005.] In C. Holtz-Bacha (Ed.), Die Massenmedien im Wahlkampf. Die Bundestagswahl 2005 (pp. 213-233). Wiesbaden, Germany: VS Verlag für Sozialwissenschaften.

Rainie, L., Cornfield, M., \& Horrigan, J. (2005). The Internet and campaign 2004. Retrieved February 28, 2007, from http: //www. wewinternet.org/pdfs/PIP_2004_Campaign.pdf

Roberts, G. K. (2006). The German Bundestag election 2005. Parliamentary Affairs, 59, 668-681.

Schmidt, J. (2007). Social software: Facilitating information-, identity- and relationship management. In T. N. Burg \& J. Schmidt (Eds.), BlogTalk reloaded. Social software-research and cases (pp. 31-49). Vienna, Austria, \& Norderstedt, Germany: Books on Demand.

Schmidt, J., \& Wilbers, M. (2006). Wie ich blogge?! Erste Ergebnisse der Weblogbefragung 2005. [How am I blogging?! First results of the Weblog survey 2005.] Retrieved February 28, 2007, from http:// $141.13 .22 .238 /$ fonkblog/pdf / fonkbericht0601.pdf

Schoen, H., \& Faas, T. (2005). When methodology interferes with substance: The difference of attitudes toward e-campaigning and e-voting in online and offline surveys. Social Science Computer Review, 23, 326-333.

Schulz, W., Zeh, R., \& Quiring, O. (2005). Voters in a changing media environment: A data-based retrospective on consequences of media change in Germany. European Journal of Communication, 20, 55-88.

Schweitzer, E. J. (2005). Election campaigning online. German party websites in the 2002 national elections. European Journal of Communication, 20, 327-351.

Shirky, C. (2003). Power laws, weblogs and inequality. Diversity plus freedom of choice creates inequality. In J. Engeström, M. Ahtisaari, \& A. Nieminen (Eds.), Exposure. From friction to freedom (pp. 77-81). Helsinki, Finland: AULA.

Sixtus, M. (2005). Massenmedium. Blogosphäre: Kommunikationsgeflecht und Marketingfaktor. [Mass medium. The Blogosphere: Communication network and factor in marketing.] c't, 19, 148-152.

Stanyer, J. (2006). Online campaign communication and the phenomenon of blogging. An analysis of web logs during the 2005 British general election campaign. Aslib Proceedings, 58, 404-415.

Sunstein, C. (2001). Republic.com. Princeton, NJ: Princeton University Press.

Wasserman, S., \& Faust, K. (1994). Social network analysis. Methods and applications. Cambridge, UK: Cambridge University Press.

Wüst, A. M., \& Roth, D. (2006). Schröder's last campaign: An analysis of the 2005 Bundestag election in context. German Politics, 15, 439-459.

Wüst, A. M., Schmitt, H., Gschwend, T., \& Zittel, T. (2006). Candidates in the 2005 Bundestag election: Mode of candidacy, campaigning and issues. German Politics, 15, 420-438.

Steffen Albrecht (steffen. albrecht@tu-harburg. de) is a research assistant and $\mathrm{PhD}$ student at the Institute of Technology and Society at Hamburg University of Technology. His current research focuses on the social and political impacts of information and communication technologies.

Maren Lübcke (maren.luebcke@tu-harburg.de) is a research assistant and $\mathrm{PhD}$ student at the Institute of Technology and Society at Hamburg University of Technology. She holds a diploma in sociology and specializes in the field of communication, new media research, and social network analysis.

Rasco Hartig-Perschke (perschke@tu-harburg. de) is a research assistant and $\mathrm{PhD}$ student at the Institute of Technology and Society at Hamburg University of Technology. His published work includes articles on weblog communication and communication theory. 